\title{
O crack em Manguinhos: a experiência de agentes sociais do território
}

\author{
The crack in Manguinhos: the experience of social agents of the \\ territory
}

Viviani Cristina Costa', Marize Bastos da Cunha ${ }^{2}$

DOI: 10.1590/0103-11042019S802

RESUMO O artigo tem como objetivo construir o conhecimento sobre o fenômeno do crack em Manguinhos, um bairro da cidade do Rio de Janeiro, a partir da construção compartilhada do conhecimento e, portanto, da inclusão do saber popular e das experiências de vida das pessoas que vivenciam de alguma maneira a problemática no território. Trata-se de uma pesquisa participante, um método qualitativo que permite levantar e circular conhecimentos e experiências da problemática em questão, assim como debatê-los. Observou-se que a constituição e transitoriedade das cenas de uso de crack foram determinadas por uma diversidade de agentes, poderes e ações, como a organização do tráfico de drogas, a implantação da Unidade de Polícia Pacificadora, a relativa proteção do usuário e o acesso facilitado à droga. Verificou-se distintas e, por vezes, conflituosas ações do Estado nas cracolândias, como ações de recolhimento compulsório em contraponto as ações de saúde realizadas pelo Consultório na Rua. Outros pontos levantados foram o apoio social, principalmente vinculado ao trabalho voluntário de moradores e as instituições religiosas; e a relação entre uso de crack e precarização do trabalho. O conhecimento produzido contribui no debate e construção de ações.

PALAVRAS-CHAVE Cocaína crack. Saúde mental. Vulnerabilidade social.

\begin{abstract}
The article has as objective build the knowledge about the phonomena of crack in Manguinhos, a neighborhood in the north of Rio de Janeiro, from the shared knowledge construction and, therefore, the inclusion of popular knowledge and through the life experience of people's life who somehow lived it in the territory. It is a participating research, a qualitative method that allows to bring up and circulate knowledge of the problematic and experiences in question, as well as debate them. It was observed that the constitution and transitority of crack use scenes in Manguinhos were determined by a diversity of agents, power and actions, such as drug traffic organization, the implementation of a Pacified Police Unit, a relative protection for the crack user and facilitated access to the drug. It was virified distinct and, at times, conflicting actions of the State in the so called crackolands, such actions of compulsory arrestmentand performed in contrast with health actions carried out by teams of Street Cabinet. Other points raised were the presence of social support, mainly related to religious institutions and the volunteer work of local population; and it was shown relations established between work and the use of crack. The knowledge produced contributes to the debate and construction of actions.
\end{abstract}




\section{Introdução}

Até meados dos anos 80, o tratamento em saúde para os usuários de drogas estava pautado na internação e na abstinência nos grandes manicômios. E, portanto, em sintonia com o discurso jurídico-político proibicionista de erradicação das drogas na sociedade, por estas se constituírem em um risco à saúde e à segurança do indivíduo e da população.

Influenciada pela experiência da Reforma Psiquiátrica Italiana e incorporada pela Reforma Sanitária Brasileira e a construção do Sistema Único de Saúde (SUS), a Reforma Psiquiátrica Brasileira transformou o panorama das políticas públicas de saúde mental no país ao questionar as bases da psiquiatria e o manicômio'. Não é possível abarcar o impacto social dessa mudança sem mencionar que sua origem se encontra dentro do movimento social, com uma intensa articulação de distintos atores da sociedade civil, cujas demandas e necessidades puderam ser transformadas em políticas públicas de saúde².

O que, sem dúvida, foi preponderante para a mudança no patamar de discussão sobre a política de drogas no Brasil contribuindo para alguns avanços nas políticas de saúde pública, principalmente na primeira década do século XXI, com a implantação da Política para a Atenção Integral a Usuários de Álcool e Outras Drogas $^{3}$ e a ampliação da cobertura assistencial de serviços substitutivos especializados de base comunitária. Dentre eles, os Centro de Atenção Psicossocial para usuários de Álcool e outras Drogas (Caps AD), o Consultório na Rua (CnaR), as Unidades de Acolhimento (UAA) e os leitos para desintoxicação em hospital geral.

No entanto, no contexto nacional atual, esses avanços estão ameaçados. Vivemos um momento de grave crise política que culminou com o acirramento das posições partidárias e obviamente vem repercutindo nas políticas de drogas nacionais ao provocar diversas mudanças, as quais vão na contramão do que havia sido consolidado com a Reforma Psiquiátrica Brasileira. Estamos falando de decisões políticas que têm colocado interesses específicos à frente das necessidades coletivas da sociedade, como o retorno de uma lógica.

A gestão Bolsonaro, iniciada em janeiro de 2019, conta com representantes de forças conservadoras dentro do campo da saúde coletiva e saúde mental, os quais reafirmam o hospital psiquiátrico como lugar privilegiado no tratamento e redirecionam o financiamento para as instituições de caráter manicomial, dentre elas, as comunidades terapêutica ${ }^{4}$. Esses pontos demonstram uma ruptura com o que se construiu com o processo da Reforma Psiquiatra Brasileira e demarcam uma série de retrocessos que a área vem sofrendo desde o ano de 2017 e se aprofunda no início desse governo.

Em momentos como esse, faz-se ainda mais necessário dar visibilidade as vozes que se encontram silenciadas na sociedade brasileira. A voz da periferia, a qual sofre com a 'Guerra às Drogas' e a disputa armada nos territórios de favelas, precisa ser incluída no debate e formulação das políticas do campo da saúde mental, álcool e outras drogas.

A este respeito, trazemos aqui resultados referentes à pesquisa sobre o fenômeno do crack no Complexo de Favelas de Manguinhos que, procurando compreender tal fenômeno, voltou-se fundamentalmente para o lugar de fala de moradores que atuam em ações sociais neste território, acompanhando as cenas de uso, com todas suas alterações, e mudanças no que se referem aos fluxos de comercialização da droga. E sobretudo, seguindo a trajetória das pessoas que passam a usar o crack. Incorporando referenciais teóricos metodológicos que partem de práticas dialógicas, foi proposto um caminho de estudo que incorpora o ponto de vista popular, rompendo com a investigação científica tradicional.

A pesquisa se propôs a fazer uma discussão a partir do ponto de vista popular, o qual vivencia a experiência da problemática do crack em seu território e tudo que dele decorre. Assim, considerando o espaço do território de Manguinhos, buscou-se apreender a complexidade do fenômeno do crack através daquilo 
que Bourdieu ${ }^{5}$ denomina espaço de pontos de vista dos agentes sociais envolvidos, tendo-se em vista os processos de vulnerabilização e as múltiplas determinações que o perpassam. Uma forma de construção de conhecimento através da qual seja possível abrir canais de escuta e diálogo com aqueles que estão envolvidos com os problemas que buscamos examinar e mesmo resolver, para então fazer aparecer o que resulta do confronto de visões de mundo diferentes ou antagônicas ${ }^{\mathbf{5}}$.

Os agentes sociais desse estudo, denominados por Cunha como mediadores na comunidade $^{6,7}$, são figuras de liderança no território em função de sua experiência nas lutas locais, por seu conhecimento do jogo político e sua interlocução com agentes sociais de fora da favela. Assumem esse lugar de modo relativamente autônomo da esfera do poder instituído na favela, seja o oficial por meio da ação de instituições públicas marcadas por jogos políticos de cooptação e clientelismo, seja poderes paralelos, como o narcotráfico e as milícias, que impõem acordos e limites para a atuação de pessoas e organizações dentro do território. A particular forma de atuação destes mediadores na favela, através da proximidade cotidiana com os moradores, reforça uma experiência comum com eles. Sendo assim, ele produz uma visão a respeito dos problemas na localidade, a partir de um outro lugar que possivelmente lhe dá um horizonte de visibilidade crítica da qual ele pode analisar as implicações das relações de poder na favela, a atuação dos mediadores externos e interpretar a ação e experiência dos demais moradores ${ }^{6}$. Sendo assim, eles se aproximam do que Bourdieu chama 'analisadores práticos':

situados em pontos onde as estruturas sociais 'trabalham' e trabalhados por isso pelas contradições dessas estruturas, eles são obrigados, para viver e sobreviver, a praticar uma forma de autoanálise que dá acesso, bastante amiúde, às contradições objetivas que os possuem, e às estruturas objetivas que se expressam através delas5(591,592).
Portanto, o mediador privilegiado na pesquisa foi o morador de Manguinhos, que é atuante em questões que passam pelo coletivo, participando, por exemplo, de fóruns, colegiados ou conferências e, por isso, reconhecido pela população. A partir dessa perspectiva algumas perguntas guiaram o estudo: Como estes agentes sociais vivenciam e como explicam o fenômeno do crack na localidade selecionada? Quais os principais problemas e necessidades por eles levantadas? Quais as respostas sociais, que foram e estão sendo produzidas, em relação ao crack? Como as políticas públicas de drogas estão sendo produzidas no território?

\section{Métodos}

A pesquisa foi desenvolvida entre 2015 e 2016 no Complexo de Manguinhos. Trata-se de um território vulnerabilizado, localizado na zona norte da cidade do Rio de Janeiro e que possui cerca de 36.160 habitantes ${ }^{\mathbf{8}}$, espalhados em 15 comunidades. Em relação aos equipamentos de saúde, conta com a cobertura de 13 equipes de Estratégia Saúde da Família (ESF), uma equipe de CnaR e um Centro de Atenção Psicossocial (Caps II).

O estudo integrou-se a um programa maior de pesquisas desenvolvido regularmente em Manguinhos, sendo que uma das principais características é a abordagem metodológica, na qual se pautou na pesquisa ação, com o permanente diálogo com coletivos e moradores da localidade, bem como apoio às redes sociais existentes no território. Esta integração favoreceu o desenvolvimento da investigação, cuja complexidade vinculava-se diretamente ao objetivo de compreender o problema do crack, a partir do ponto de vista de agentes sociais locais, cujo acesso depende diretamente de relações de confiança e credibilidade construídas ao longo do tempo, envolvendo muitas vezes lutas em comum.

Recorreu-se, portanto, a uma modalidade de pesquisa participante, sob a ótica da construção 
compartilhada do conhecimento 9 , buscando dialogar com os distintos agentes sociais selecionados, considerando que eles acumulam um conhecimento e uma experiência, fundamentais ao avanço da compreensão do território e de problemas nele enfrentados. Dessa forma, os agentes sociais são também investigadores e estudiosos e não objeto da pesquisa ${ }^{10}$.

Os critérios de inclusão dos participantes foram: ser morador do território ou atuar na localidade participando de fóruns de debate e de intervenções locais. O critério de exclusão foi ter idade inferior a 18 anos. Os selecionados foram indicados por lideranças e profissionais que acompanham a dinâmica social de Manguinhos e foram incluídos na pesquisa após aceitarem a participação. Dentre os participantes estavam presentes conselheiros de saúde, membros de movimentos sociais, pessoas ligadas a instituições religiosas e que desenvolviam ações nas cenas de uso de crack, estudantes, professores e pesquisadores.

A pesquisa comportou diferentes fases, dentre elas a imersão no campo, entrevistas abertas e oficinas de discussão, respectivamente. Foram feitas oito entrevistas, com pessoas entre 22 a 60 anos, sendo seis do sexo feminino e dois do masculino. Seis delas vivem em diferentes localidades de Manguinhos. Duas não moram na região, sendo que uma delas residiu no território a maior parte de sua vida, ainda atuando em lutas coletivas para a melhoria das condições de vida da comunidade. Apenas uma nunca residiu na localidade do estudo, mas a relação estabelecida entre Manguinhos e os territórios nos quais já morou, e mora, contribui para o conhecimento da problemática do estudo. Todos mencionaram que têm ou já tiveram familiares com moradia no território.

Após a sistematização dos dados produzidos nas entrevistas, foram realizadas duas oficinas com intuito de debater, a partir do conhecimento produzido, os problemas considerados como fundamentais pelos agentes sociais. Participaram dessa fase quinze pessoas, todos agentes sociais moradores de Manguinhos e atuantes no território, sendo onze do sexo feminino e quatro do sexo masculino. Quatro dos participantes foram entrevistados na primeira fase da pesquisa.

A análise de dados foi realizada ao longo e posteriormente à pesquisa de campo. A pré-análise constitui-se da transcrição das entrevistas na íntegra e conservação das gravações e das imagens audiovisuais referentes às oficinas. Em seguida, foi realizada uma análise estrutural, entrevista por entrevista, com leitura flutuante objetivando levantar os dados pertinentes. Posteriormente o material foi organizado de forma horizontal, com intuito de elencar as repetições temáticas organizadas a partir dos três eixos principais contemplados pelo estudo: Gênese e Emergência da problemática do crack em Manguinhos; Reprodução e Desdobramentos; Respostas que foram dadas e ações necessárias. A partir de cada eixo emergiram temas relacionados, alguns já previstos na fase exploratória e outras delineadas ao longo do trabalho de campo a partir de informações e conhecimento exposto pelos agentes.

A pesquisa foi aprovada pelo Comitê de Ética em Pesquisa sob $n^{\circ}$ CAAE 32868814.0.0000.5263. Objetivando-se manter o anonimato dos participantes, optou-se por identificá-los por nomes fictícios.

\section{Resultados e discussão}

Serão explicitados parte dos resultados encontrados, organizados em tópicos, que se inter-relacionam.

\section{Constituição e transitoriedade das cenas de uso}

A chegada do crack em Manguinhos, que segundo os agentes sociais ocorreu em torno do ano de 2006, provoca mudanças que interferem na dinâmica do território. A constituição das cenas de uso, antes inexistentes, é uma delas.

A maior cracolândia foi estabelecida no período anterior a entrada do Programa de 
Unidade de Polícia Pacificadora (UPP) e estava localizada na comunidade da Coreia, mais especificamente no entorno do campo de futebol desativado. No mesmo local, existe uma das bocas de fumo do Complexo, o que aumentava a vulnerabilidade do usuário em relação ao traficante. Os relatos descrevem diversas cenas de violência física e psicológica, assim como péssimas condições de salubridade. Os usuários conviviam no mesmo espaço com muito lixo, além da presença de animais como porcos e galinhas. Alguns agentes sociais fazem referência à área como 'Vale dos Ossos Secos' e 'Sodoma e Gomorra' (cidades de uma passagem da bíblica que foram destruídos por Deus devido à prática de atos imorais, segundo a moral dos antigos israelitas).

[...] e a gente viveu coisas horríveis, começou a ver a comunidade mudar totalmente, gente estranha, eu ficava apavorada. Teve uma época, antes da pacificação, tem o campo na Coréia, é um campo grande, era um campo de futebol, era bastante ativo né, vinha time futebol que vinha jogar. E com a introdução do crack, ele virou campo onde todos os dependentes de crack ficavam ali 24 horas por dia [...]. E era muito triste porque a gente assistia muitas vezes, quando eles erravam em alguma coisa, eles levarem surras. (Clara).

Durante a pesquisa as cenas de uso estavam localizadas em distintas regiões do território, no geral em áreas localizadas mais a borda, e eram constituídas por um número menor de pessoas. A cena de uso localizada na Coreia ainda existia, mas com um número reduzido de usuários. Portanto, com uma configuração bem distinta da relatada antes da entrada da UPP.

Em acordo com achados de outras pesquisas ${ }^{11-13}$, observou-se que tanto a constituição, quanto a transitoriedade das cenas de uso de crack foram determinadas por uma diversidade de agentes, poderes e ações, tais como: a organização do tráfico de drogas, a implantação da UPP, as ações de recolhimento compulsório, a relativa 'proteção' do usuário e o acesso facilitado à droga.
O tráfico ele chama pra si né, porque é o seu lucro. Hoje eles determinam as áreas de uso principalmente de crack. Cocaína não. Cocaína e maconha usam-se em qualquer lugar dentro do território que tem o tráfico, é permitido. O crack já não é assim. O crack tem um lugar específico. (Jean).

[...] muitos são da Baixada... então é uma porcentagem muito pequena, pequena mesmo de pessoas do Jacaré e Manguinhos. Isso foi uma das coisas que me chamou a atenção. Porque né a gente acaba questionando. Primeiro porque na Baixada a maioria é Milícia, então não tem essa questão do tráfico tão latente assim e dependente na rua, de fato eles morrem porque eles matam. Então tem essa questão também da migração deles quando a gente acaba perguntando, eles falam por ser um local protegido, vários já me falaram que é onde eles podem usar tranquilamente sem ser morto. Na Baixada eles de fato exterminam os dependentes. (Luiza).

Luiza, ao comparar a relação entre o usuário de crack com o tráfico e a milícia, aponta a relativa proteção do usuário como um dos fatores que explicam sua migração. Chamamos de relativa, primeiro porque também é observada violência com os traficantes. $E$ segundo, porque a migração de algumas cenas para as vias públicas provocou uma maior rejeição social e ações desastrosas por parte da prefeitura, de repressão e violação dos direitos humanos, através da política de recolhimento compulsório.

No que se refere a organização do tráfico local, observa-se diferença de regras e circulação tanto em relação à droga quanto em relação ao usuário de crack e o usuário de maconha e/ou cocaína. Assim, no território a facção criminosa determina quais as bocas que vendem o crack e quais não vendem. Mudanças de gerentes do tráfico também podem gerar mudanças na comercialização da substância, nos locais de uso e, até mesmo, restrição de ocupação dos usuários a determinados espaços justificadas pelo estigma em torno da figura do cracudo, que é o usuário sem controle, que pode dar problema. 
Verifica-se ainda distinções nas relações pessoais estabelecidas entre traficante/usuário de crack e traficante/usuário de maconha/ cocaína. Por um lado, o tráfico valora negativamente o consumo de crack, mas, por outro, mantém a venda da droga, certamente por sua rentabilidade. $\mathrm{O}$ que por sua vez gera tensionamentos entre usuários, traficantes e a própria população.

\section{A emergência do crack, processos de vulnerabilização e pobreza urbana}

Outro achado da pesquisa se refere as relações estabelecidas entre trabalho e uso de crack, sendo levantadas três principais formas: a figura do usuário catador associada aos ferros velhos; a prostituição; e os denominados aqui como 'bicos'. Em todos os três tipos foram observadas uma relação direta entre a desvalorização financeira da atividade realizada por se tratar de um sujeito que faz uso de crack, violência simbólica e exposição a danos à saúde.

Em relação aos profissionais do sexo aponta-se também a relação entre uso de crack e prostituição entre adolescentes na comunidade, embora seja também visto por adultos. Observa-se como forma de organização de trabalho os agenciamentos realizados por taxistas, por outras pessoas que circulam em carros de fora da comunidade e pelos próprios moradores. A pesquisa de Bastos e Neilane ${ }^{\mathbf{1 4}}$ aponta o sexo comercial como uma fonte relevante de renda para os usuários de crack maiores de 18 anos, 7,46\% dos usuários relatam essa forma de trabalho em troca de dinheiro e/ou drogas.

Os bicos são descritos como prática comum e evidenciam uma forma de exploração das pessoas do lugar com o usuário que circula na comunidade. Os usuários são vistos como os indivíduos que aceitam fazer qualquer tipo de trabalho, como, por exemplo, limpeza, carregamentos, capina etc., por um valor muito inferior ao preço de mercado. O relato abaixo descreve cenas cotidianas que parecem se repetir.
Tem muita gente que se aproveita disso aí, quer ver uma conversa:

-Ah tem um quintal ali para poder capinar.

-Ah, arruma um cracudo.

É assim que eles falam.

-Ah, tem uma fossa para limpar, essa fossa está entupida.

-Ah, arruma um cracudo e dá dois contos que ele vem e limpa. Mas vem mesmo, ele vem e limpa mesmo. Então as pessoas se aproveitam disso. Isso não é escravo? Isso é escravizar, estão aproveitando daquela situação que ele está vivendo. (Jean).

Uma hipótese levantada para essa relação de trabalho estabelecida é o fato de a maior parte dos usuários não serem da mesma localidade. Não existe uma relação de afetividade e solidariedade previamente construída, ele não tem família no local, é alguém desconhecido e, pior, para muitos ele degrada, deixa à margem o lugar. Talvez essa não-relação, a ausência de capital simbólico e cultural nas relações sociais estabelecidas permita uma relação de apropriação de uma força de trabalho extremamente injusta.

\section{Entre a solidariedade, o desprezível e a política pública}

Por outro lado, foram registradas ações de apoio social desempenhadas por moradores e pelas igrejas, que se constituem como possibilidade de ampliação da rede social de suporte desses sujeitos. Levantamos algumas experiências, como a de Conselheiros de Saúde, que reivindicaram e conquistaram um equipamento de saúde mental como o Centro de Atenção Psicossocial (Caps) no território; ações como a de 'Luiza', que em conjunto com um familiar oferecia alimentos, cuidados de higiene e orientações em relação aos equipamentos de saúde nas cenas de uso; e ações de acolhimento das igrejas, ofertando alimentos, roupas e orações durante as madrugadas.

Assim, em diálogo com Freire ${ }^{15}$, podemos afirmar que diante de uma situação limite, 
inéditos viáveis são construídos por moradores através de diferentes estratégias de apoio e proteção social. São ações que demonstram a pluralidade de Manguinhos, que não se trata apenas de um território de ausências (de educação, saúde, assistência social, direitos humanos), mas um lugar também de vidas desejantes. Foi possível construir alternativas e respostas em prol de um coletivo, em prol de uma sociedade menos injusta e mais solidária. Esse tipo de leitura não é uma análise ingênua que percebe tais ações como a possibilidade de transformação de uma realidade extremamente iníqua, mas uma análise que propõe dar visibilidade a outros discursos. São narrativas que revelam caminhos distintos das respostas desumanas de retirada/expulsão/limpeza do problema usuário de crack para áreas degradadas e/ou periféricas.

Em uma cidade na qual as remoções de certos grupos de pessoas e modos de existência são uma constante, existe muito o que aprender com as pessoas que habitam esses territórios, sua capacidade de criar e recriar sua própria existência em um meio que lhes impõe impossibilidades. Tecendo redes de solidariedade e práticas de resistência.

Para Valla ${ }^{16}$, o apoio social é capaz de produzir efeitos emocionais e/ou comportamentais positivos, tanto para quem oferece como para quem o recebe. $\mathrm{O}$ apoio mútuo e a solidariedade são ferramentas humanas que auxiliam tanto na prevenção de doenças como no suporte durante o processo de adoecimento. Portanto, relaciona-se com a manutenção e/ ou recuperação da saúde, seja pela prevenção, seja pela cura.

No que concerne ao campo das políticas públicas, verificou-se distintas e, por vezes, conflituosas ações do Estado. Como as ações de recolhimento compulsório realizadas pela segurança pública e assistência social, em contraponto às ações de saúde realizadas pelas equipes de CnaR. O que denota um mesmo Estado agindo por meios de repressão, de violações de direitos, em contraponto às ações que visam a garantia de direitos e de acesso.

\section{A dinâmica de um território conflagrado}

Acompanhamos diariamente inúmeros relatos e denúncias feitos por moradores do território de Manguinhos em espaços instituídos, como o Colegiado Gestor Intersetorial de Manguinhos (CGI) do Teias Escola Manguinhos, através do contato com lideranças de grupos organizados como o Fórum Social de Manguinhos e a Organização Mulheres de Atitude (OMA) ou pelas páginas nas mídias sociais. Tais relatos trazem à tona um território e uma população que sofre com a opressão causada pelo Estado e pelo tráfico de drogas, seja pela guerra às drogas, seja pelas guerras entre facções rivais na disputa armada pelo controle dos territórios. Assim como a pouca visibilidade dada às mortes e ao adoecimento causado à população.

As falas abaixo foram expostas nas entrevistas e oficinas realizadas e exemplificam parte das denúncias apontadas:

É uma prisão dentro de casa. Essa guerra às drogas também adoece. (Cristina).

Quando a escola fecha as crianças voltam para o meio do tiroteio. (Clara).

[...] estamos com medo. Estamos nos sentindo preso dentro de casa. Não sei onde vamos parar. (Teresa).

Na pesquisa, a ação policial neste território foi vista como frequentemente discriminatória e ilegal, totalmente diferente daquela praticada em outras partes da cidade, como, por exemplo, nos bairros de classe média e alta. Apontam o racismo e a desigualdade social como fatores estruturais que legitimam a morte na periferia, invisibiliza o extermínio de jovens negros e gera sofrimento psíquico nos sobreviventes.

A conscientização da situação de iniquidade significa uma abertura à compreensão das estruturas sociais como modos de opressão e violência em uma sociedade marcada pelos processos de desigualdade e exclusão. 
Reconhecer essa diferença histórica possibilita a construção de coletivos e processos de resistência, como colocado por Miguel:

A sociedade tem um grupo que é privilegiado. $E$ esse grupo de privilegiado quer tirar a nossa capacidade de sonhar, de nos indignar. E aí estar nesse momento aqui em grupo vê que a gente não está sozinho [...]. Talvez a gente não estaria de pé, porque esses privilegiados não querem que a gente esteja de pé. (Miguel).

\section{O que os mediadores compreendem como ações necessárias?}

Verifica-se que dentro das favelas a questão foi e ainda é majoritariamente tratada como uma questão de segurança pública. Sendo reconhecida a necessidade de ações em saúde, enfocando também aspectos da prevenção e não apenas do tratamento. A prevenção é apontada principalmente por uma preocupação com as crianças e adolescentes do território. Nesse sentido, a proximidade com o tráfico é vista como um elemento de preocupação pelos moradores.

Coloca-se como necessidades o reconhecimento do saber popular por parte dos equipamentos/serviços já existentes. Valla17 aponta a dificuldade dos profissionais em compreender o que os membros das chamadas classes subalternas dizem. $\mathrm{O}$ autor acredita que a dificuldade está mais relacionada a postura na qual o profissional coloca-se, do que com questões de outras ordens. Assinalamos como imperativo a inclusão do saber popular na discussão, na crítica e no levantamento das necessidades atuais das políticas públicas sobre drogas. A associação entre o conhecimento local e outras formas de conhecimento pode potencializar o desenvolvimento de práticas mais democráticas, menos normativas e construir caminhos para movimentos de resistência necessários frente a lógica do governo atual.

Outros pontos levantados são o fortalecimento e ampliação de uma rede de atenção psicossocial humanizada, que esteja articulada a políticas de moradia e de trabalho. Assim como a necessidade de diálogo com o usuário para melhor percepção do que ele traz como necessidade. É interessante apontar que na pesquisa 'A gênese social do crack' os usuários, ao serem questionados sobre o que esperam de um tratamento para o seu problema com as drogas, reivindicam um pacote de direitos sociais, como serviços de saúde, moradia, educação, emprego, alimentação e banho' ${ }^{\mathbf{1 8}}$.

\section{Considerações finais}

Diante de todo o percurso histórico do caminhar das Reforma Psiquiátrica e diante da disputa de poder existente no campo das políticas de drogas, reafirmamos a necessidade em visibilizar o lugar de fala da população que experiencia de maneira injusta questões relativas às drogas. As falas dos agentes sociais revelam histórias e vivências que descortinam a ausência da garantia de direitos, o cotidiano atravessado pela espetacularização da violência e o descompasso das políticas públicas. Revelam também momentos de lutas, conquistas e a constituição de redes de solidariedade para enfrentar a precariedade da vida. No entanto, o conhecimento produzido por esse grupo de pessoas pouco entra no debate ou mesmo na construção do conhecimento científico.

A perspectiva de reunir, confrontar e estabelecer diálogos entre distintos saberes e perspectivas, pretende fornecer maior qualidade e contextualização à produção de conhecimento. Tem como intuito possibilitar aos diferentes grupos sociais a ampliação de sua capacidade de compreender, interferir e transformar solidariamente uma dada realidade desfavorável ${ }^{19}$. Em contexto de territórios em processos de vulnerabilização, como o território de Manguinhos, aumentar o poder político e cidadão da população, através de práticas de produção de conhecimentos sobre os problemas locais, se torna um imperativo ${ }^{19}$. 
Ao mesmo tempo, o conhecimento produzido pelos mediadores amplia as possibilidades de respostas à problemática do crack frente aos desafios vivenciados pelas instituições de saúde e políticas públicas do campo. Entendemos a dimensão da experiência como um elemento aglutinador de forças sociais nos processos de autoconhecimento e autodiagnóstico coletivo. O que contribui para a análise das condições de saúde, o planejamento de ações, bem como para o fortalecimento de movimentos de resistência necessário as iniquidades colocadas.

Ressaltamos o potencial desse tipo de estudo ao contribuir para a articulação dos diferentes agentes sociais do território, pautado em uma perspectiva de ciência engajada e emancipatória ${ }^{20}$. Mesmo ocupando posições distintas no lugar, a pesquisa contou com professores, conselheiros de saúde, militantes, pesquisadores, todos tinham em comum o interesse em melhorias das condições de vida para os moradores de Manguinhos. Esse objetivo comum facilita a capacidade de mobilização.

Além disso, ao emergir da participação popular na construção dialógica do conhecimento, a pesquisa contribui metodologicamente para repensar um dos dilemas vivenciados desde a constituição do SUS e que se acentua diante do atual desmonte de políticas sociais: a garantia da participação das populações nas decisões que afetam suas vidas. Nesse caso, a garantia do lugar de fala da periferia na análise dos problemas de saúde dos seus territórios.

Por fim, ressaltamos a complexidade do tema e reafirmamos que ele deve ser encarado de forma ética e responsável, articulando diferentes saberes e políticas em prol de melhorias nas condições de vida e saúde da população.

\section{Colaboradores}

Costa VC (0000-0002-5519-3570)* contribuiu para a concepção, planejamento e análise do manuscrito; para a elaboração da versão crítica do conteúdo e para a aprovação da versão final. Cunha MB (0000-0001-7509-9138) contribuiu para a análise e interpretação dos dados; para a revisão crítica do conteúdo e para a aprovação da versão final. 


\section{Referências}

1. Amarante P. Saúde mental e atenção psicossocial. 3. ed. Rio de Janeiro: Fiocruz; 2011.

2. Yasui S. Rupturas e encontros: desafios da Reforma Psiquiátrica Brasileira. [tese]. Rio de Janeiro: Escola Nacional de Saúde Pública, Fundação Oswaldo Cruz; 2006. 208 p.

3. Brasil. Ministério da Saúde, Secretaria Executiva, Coordenação Nacional de DST e Aids. Portaria $\mathrm{n}^{\mathrm{o}} 457$, de 16 de abril de 2003. Estabelece a Política do Ministério da Saúde para atenção integral a usuários de álcool e outras drogas. Diário Oficial da União. 2003. [acesso em 2020 jan 30]. Disponível em: http://bvsms.saude.gov.br/bvs/saudelegis/ gm/2003/prt0457_16_04_2003.html.

4. Brasil. Ministério da Saúde, Coordenação de Saúde Mental, Álcool e outras Drogas. Nota técnica ${ }^{\circ}$ 11/2019. Esclarece sobre as mudanças na Política Nacional de Saúde Mental e nas Diretrizes da Política Nacional sobre Drogas. Diário Oficial da União. 2019. [acesso em 2020 jan 30]. Disponível em: http://pbpd. org.br/wp-content/uploads/2019/02/0656ad6e.pdf.

5. Bourdieu P. A miséria do mundo. Petrópolis: Vozes; 1997.

6. Cunha MB. Grotão, Parque Proletário, Vila Cruzeiro e outras moradas: História e Saber nas favelas da Penha. [dissertação]. Niterói: Universidade Federal Fluminense; 1995.408 p.

7. Cunha MB. Nos desencontros e fronteiras: os trabalhadores sociais das favelas do Rio de Janeiro. [tese]. Niterói: Universidade Federal Fluminense; 2005. 353 p.

8. Instituto Brasileiro de Geografia e Estatística. Censo Demográfico. [acesso em 2019 abril 20]. Disponível em: http://www.ibge.gov.br/.

9. Carvalho MAP, Aciolo S, Stotz EN. O processo de construção compartilhada do conhecimento: uma experiência de investigação cientifica do ponto de vista popular. In: Vasconcelos EM. A saúde nas palavras e nos gestos: reflexões de rede de educação popular e saúde. São Paulo: Hucitec; 2001. p. 101-114.

10. Freire P. Criando métodos para a pesquisa participante: aprendendo a fazê-la através da ação. In: Brandão CR. Pesquisa Participante. 8. ed. São Paulo: Brasiliense; 2006. p. 34-41.

11. Veloso Filho CL. "Cenas de uso de crack no município do Rio de Janeiro - perfil em 2011/2012”. [tese]. Rio de Janeiro: Escola Nacional de Saúde Sergio Arouca, Fundação Oswaldo Cruz; 2013. 141 p.

12. Frúgoli Jr H, Cavalcanti M. Territorialidades da(s) cracolândia(s) em São Paulo e no Rio de Janeiro. Anuário Antropológico II. 2013; 38(2):73-97.

13. Machado KS, Simas RS. Redução de danos, insumos e experiência estética: uma análise da prática no consultório na rua do município do Rio de Janeiro. Rev. Interinst. Bras. Ter. Ocup. 2017; 1(1):67-83.

14. Bastos FI, Neilane B. Quem são os usuários de crack e/ou similares do Brasil? Perfil sociodemográfico e comportamental destes usuários: resultados de uma pesquisa de abrangência nacional. In: Bastos FI, Neilane B, organizadores. Pesquisa Nacional sobre o uso de crack. Rio de Janeiro: Icict/Fiocruz; 2014.

15. Freire P. Pedagogia do Oprimido. 17. ed. Rio de Janeiro: Paz e Terra; 1987.

16. Valla VV. Educação popular, saúde comunitária e apoio social numa conjuntura de globalização. Cad. Saúde Pública. 1999; 15(2):7-14.

17. Valla VV. A crise da interpretação é nossa: procurando compreender a fala das classes populares. Educação e Realidade. 1996; 21(2):177-90.

18. Garcia L. Apresentação. In: Souza J. Crack e Exclusão Social. Brasília, DF: Ministério da Justiça e Cidadania; Secretaria Nacional de Política de drogas; 2016. p. 11-16. 
19. Porto MFS, Pivetta F, Guimarães G, et.al. Produção compartilhada de conhecimento e cidadania: a experiência da comunidade ampliada de pesquisa-ação do Laboratório Territorial de Manguinhos, RJ. In: Toledo RF, Jacobi PR, organizadores. A pesquisa-ação na interface da saúde, educação e ambiente: princípios, desafios e experiências interdisciplinares. São Paulo: EDUSP; 2012. p. 193-229.

20. Porto MFS, Pivetta F. Por uma promoção de saúde emancipatória nos territórios urbanos: a proposta do laboratório territorial de Manguinhos. In: Czeresnia D, Freitas CM. Promoção da saúde: conceitos, reflexões, tendências. 2. ed. Rio de Janeiro: Fiocruz; 2009. p. 207-229.

Recebido em 02/06/2019

Aprovado em 11/09/2019

Conflito de interesses: inexistente

Suporte financeiro: não houve 